\title{
Stability Evaluation of an Expressway Construction Site above an Abandoned Coal Mine Based on the Overlay and Index Method
}

\author{
Qingbiao Guo ${ }^{1,2, *}$, Guangli Guo ${ }^{3}$, Yingming Li $^{4}$, Lei Wang ${ }^{1}$ and Xingwang Zhao ${ }^{1}$ \\ 1 School of Geomatics, Anhui University of Sciences and Technology, No. 168 Taifeng Road, Huainan 232001, \\ China; austwlei@163.com (L.W.); xwzhao2008@126.com (X.Z.) \\ 2 State Key Laboratory of Coal Resources and Safe Mining, China University of Mining and Technology, \\ No.1 University Road, Xuzhou 221116, China \\ 3 School of Environment Science and Spatial Informatics, China University of Mining and Technology, \\ No.1 University Road, Xuzhou 221116, China; guoguangli65@163.com \\ 4 School of Mining and Safety Engineering, Anhui University of Sciences and Technology, \\ No.168 Taifeng Road, Huainan 232001, China; yingmingli@aust.edu.cn \\ * Correspondence: qbguoaust@163.com
}

Received: 21 July 2019; Accepted: 16 September 2019; Published: 20 September 2019

check for updates

\begin{abstract}
In recent years, more and more expressways pass through the abandoned coal mine, while the surface residual subsidence of the abandoned coal mine threatens the operation safety of the expressway. It is of significance to evaluate the stability of the construction site and take reasonable managements for effectively guaranteeing the traffic safety. How to accurately evaluate the stability of the construction site is the primary problem. This study proposes a stability evaluation model using the overlay and index method and points out that the evaluation scores and weights of evaluation indices are key parameters to determine the reliability of evaluation results. To reasonably determine the evaluation score, the scoring criteria of qualitative indices is obtained by the equidistant method, while the scoring criteria of quantitative indices is obtained by establishing scoring functions. The weights of evaluation indices are got by adopting the FAHP (fuzzy analytic hierarchy process). Then the built model is applied to evaluate the stability of the Wuyun Expressway construction site, and the results show that the Wuyun Expressway construction site is basic stable. Finally, the sensitivity of indices weights on the evaluation result is analyzed with the maximum $C_{k}\left(C_{m}, p c\right)$ of $5.9 \%$ far lower than the weight change of $\pm 30 \%$, and the average residual subsidence velocity of the maximum subsidence point is $0.0456 \mathrm{~mm} / \mathrm{d}$ using a high-resolution leveling, proving the credibility of the proposed model. Research results provide new ideas and systematic technical references for the stability evaluation of the construction site above an abandoned coal mine.
\end{abstract}

Keywords: stability evaluation; expressway; abandoned coal mine; the overlay and index method

\section{Introduction}

Coal is a double-edged sword with both advantages and disadvantages. It promotes economic development and social progress, while causing serious damages to the ecological environment. Scientific mining is put forward in order to realize the harmonious coexistence of resource development and ecological protection. The essence of scientific mining is to eliminate backward production capacity and develop advanced capacity [1-3]. Eliminating backward production capacity can optimize energy structure and promote low-carbon intensive development. According to incomplete statistics, China has closed 7100 coal mines and eliminated the backward production capacity of about 550 million $\mathrm{t} / \mathrm{a}$ in the past five years. China is expected to close 12,000 coal mines by 2020, and most of them are 
underground mining. Under this background, a lot of coal mines are abandoned, which encroach on a large amount of land resources. Giving to the abandoned land a new use is of vital significance to promote the sustainable development of mining cities.

In recent years, the construction of expressways has developed rapidly in China. By the end of 2018, the total mileage of China's expressways reached 140,000 km, ranking first in the world. With the encryption of expressway network, expressways inevitably pass through abandoned coal mines, such as the Jingfu expressway passing through Xuzhou mining area and Meishan expressway crossing the Xingmei mining area [4]. Although coal mines are abandoned, the surface subsidence will still continue for a long time. Y. Guéguen detects surface residual subsidence of the mining area in northern France, which is closed for more than 20 years [5]. When the residual deformation of abandoned coal mines spreads to expressways, the original design of the geometric structure will be changed and the roadbed will be damaged along with the pavement uplift or cracking, and the expressway operation security will be threatened. Therefore, evaluating the stability of the construction site and taking reasonable managements are of significance to guarantee the traffic safety.

At present, the research results of stability evaluation can be divided into quantitative analysis and qualitative analysis [6,7]. The quantitative evaluation models are established to calculate the surface residual deformation based on mathematics and mechanics. They are usually complex and their numerous parameters are hard to obtain [8,9]. In addition, the cooperative deformation mechanism between the surface and expressway foundation is still not clear, so the results of surface residual deformation cannot truly reflect the status of expressways, thereby reducing the significance of quantitative evaluation. More and more scholars use nonlinear science to study stability qualitatively [10-12]. Although the nonlinear science can effectively evaluate the stability of complicated and fuzzy systems engineering, but the evaluation results are not convincing. This is mainly because the assignment of key parameters in the evaluation model established based on the nonlinear science lacks scientific basis. The weights and memberships of evaluation indices are assigned values by empirical methods. Although the subjective expert experience can reflect objective laws to a certain degree, the differences in subjective thinking make the results difficult to unify and to be the only one, and thus the reliability of the evaluation result is influenced [13-15]. Therefore, it is urgent to establish a simple, practical and reliable model to evaluate the stability of the expressway construction site above an abandoned coal mine.

In this paper, a new evaluation model is established based on the overlay and index method, and the assignment criteria of key parameters in the model are obtained. The model has been applied for the Wuyun Expressway construction site and good effects have been achieved. This work is not only of general interest to the professional public, but also provides technical support for the stability evaluation of similar engineering projects.

\subsection{Study Area}

Wuyun Expressway between Wuzhi and Yuntai Mountain is located in Xiuwu and Wuzhi County in Jiaozuo City, China. With the overall length of about $37 \mathrm{~km}$, it starts from the northern end of Zhengyun Expressway and extends northward into Yuntai Mountain in Henan province. The sections of $\mathrm{K} 29+335-\mathrm{K} 33+000$ pass through the abandoned coal mine (Figure 1). The sections of K30 + 950-K31 + 700 are above the abandoned Guhanshan coal mine and sections of $\mathrm{K} 31+700-\mathrm{K} 32+950$ are above the abandoned Wucun coal mine. The rough process of mine closure in Wucun coal mine results in the loss of information in related working faces. Based on the collected drawings and field research results, this paper divides the mining region of Wucun coal mine into six areas, as shown in Figure 1. Table 1 shows the detailed information of goafs and coal storage areas under the Wuyun Expressway. 


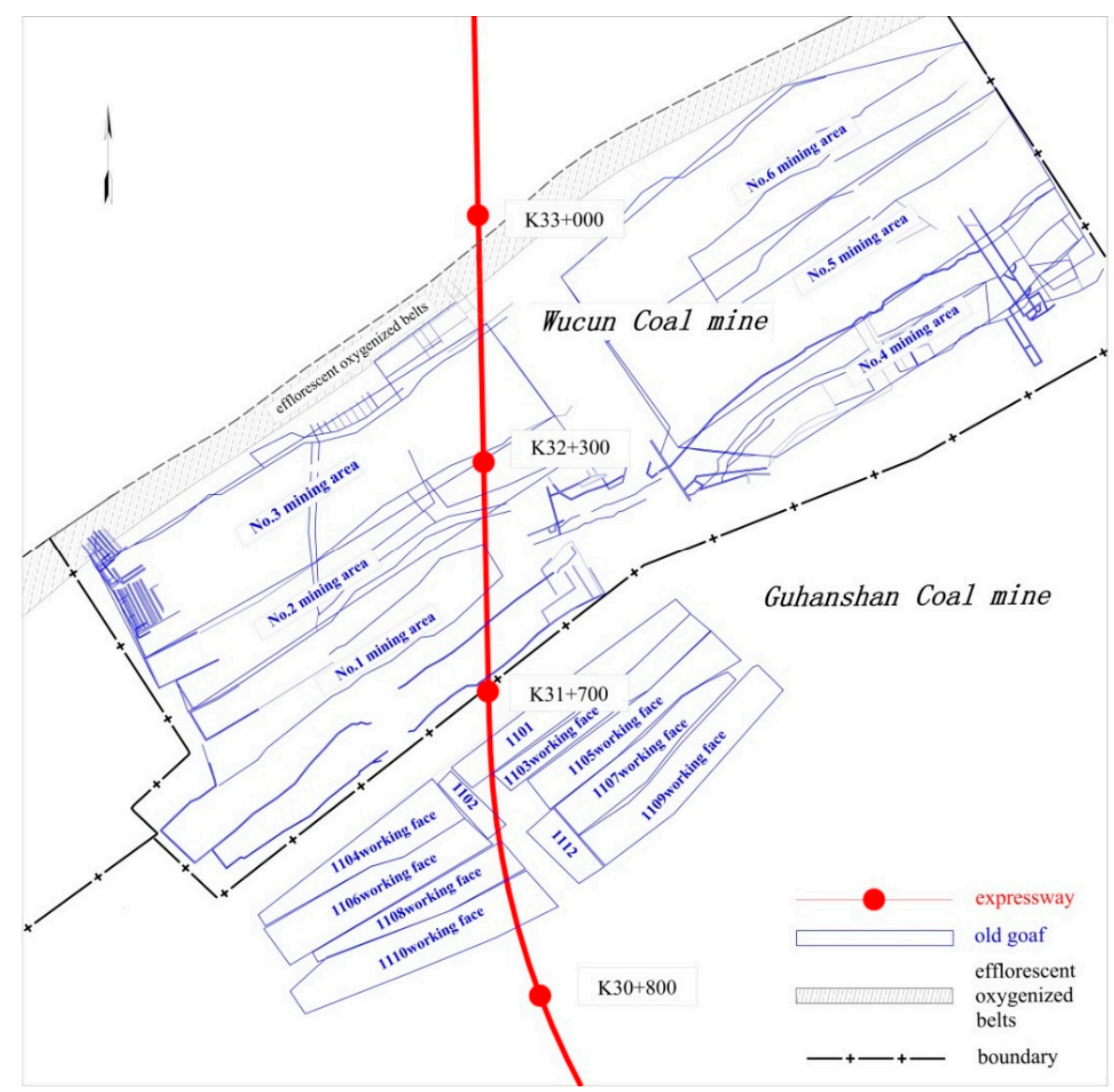

Figure 1. Sketch map of the position relationship between the Wuyun Expressway and abandoned coal mine in the investigated area.

Table 1. Distribution of the goaf and coal storage areas under Wuyun expressway.

\begin{tabular}{cccccccc}
\hline Mileage & Length/m & $\begin{array}{c}\text { Mining } \\
\text { Area }\end{array}$ & Type & Thickness/m & Depth/m & $\begin{array}{c}\text { Mining } \\
\text { Technology }\end{array}$ & $\begin{array}{c}\text { Production } \\
\text { Situation }\end{array}$ \\
\hline $\mathrm{K} 29+340-\mathrm{K} 30+950$ & 1610 & $\begin{array}{l}\text { Guhanshan } \\
\text { Coal Mine }\end{array}$ & Coal storage & $5.0-5.6$ & $556-884$ & Undeveloped \\
\hline $\mathrm{K} 30+950-\mathrm{K} 31+150$ & 200 & $\begin{array}{l}\text { Guhanshan } \\
\text { Coal Mine }\end{array}$ & Goaf & $5.0-5.1$ & $500-556$ & Long wall caving & Depleted \\
\hline $\mathrm{K} 31+150-\mathrm{K} 31+545$ & 395 & $\begin{array}{l}\text { Guhanshan } \\
\text { Coal Mine }\end{array}$ & Goaf & $5.0-5.1$ & $420-500$ & Long wall caving & Depleted \\
\hline $\mathrm{K} 31+545-\mathrm{K} 31+700$ & 155 & $\begin{array}{l}\text { Guhanshan } \\
\text { Coal Mine }\end{array}$ & Coal storage & $5.0-5.1$ & $417-420$ & Undeveloped \\
\hline $\mathrm{K} 31+700-\mathrm{K} 32+950$ & 1250 & $\begin{array}{l}\text { Guhanshan } \\
\text { Coal Mine }\end{array}$ & Goaf & $2.0-6.0$ & $158-417$ & Long wall caving & Depleted \\
\hline
\end{tabular}

In the study area, the surface is of a gentle slope shape without runoff. The basic outline of the geological structure inclines to the southeast. The monoclinic structure is formed to the northeast. The average inclination is $130^{\circ}$, and the average angle is $15^{\circ}$. The Quaternary Pleistocene alluvial strata are mainly in the shallow ground with the thickness between $80 \mathrm{~m}$ and $300 \mathrm{~m}$. They mainly consist of silty clay, silt and cobble layer mixed with silt and silty clay. The Permian strata are mainly in the deep formation, and they are made of mudstone, sandstone, coal seam and sandy mudstone.

\subsection{Influence Factors}

The stability of the expressway construction site above an abandoned coal mine is closely related to many factors, such as mining thickness, geological structure, loose layer thickness and other factors, 
which is an extremely complex and vague systems engineering $[4,16,17]$. Based on the existing research results, nine independent influence factors were selected.

(1) Rock mass structure. It is made up of the structural plane and structural body. It is the most fundamental factor that reflects the integrity of the rock structure. Generally, if the structure of the rock mass is relatively complete with small changes and weak joint fissure development, the abandoned coal mine has good stability. That is, the construction site is stable. Otherwise, it is unstable.

(2) Fractured rock strength. The fractured rock mass is compacted under external loads, causing residual subsidence. When the external load is constant, the strength of the fractured rock mass is lower, along with weaker resistance to deformation, larger compressible deformation space and bigger potential residual subsidence. At this point, the stability of the construction site is low. Otherwise, the stability is high.

(3) (3) Hydrological characteristic. Under the long-term immersion of mine water, the shear strength of rock mass will be reduced due to the lubrication effect of mine water, and the rock mass is softening, which will reduce its bearing capacity. In addition, the dissolution and corrosion of rock mass caused by mine water can increase the void and permeability of rock mass, destroying the rock mass integrity. Therefore, the larger the mine water in the abandoned coal mine, the lower the stability of the construction site is.

(4) Loose layer thickness. The overlying loose layers can absorb uneven deformation, making the surface residual subsidence gently. The bedrock direct exposure to the surface will increase the surface residual subsidence, and decreasing the stability.

(5) Depth-thickness ratio $(\mathrm{H} / \mathrm{M})$. It refers to the ratio of the burial depth to mining thickness of the coal seam. When the ratio is smaller, the external load disturbance can affect the water-flowing fractured zone. Then the compression of cavity and voids among the fractured rock mass forms the active space, and leads to surface residual subsidence. As the ratio increasing, the thickness of the bend zone increases, which can decrease the residual subsidence effectively. That is, the construction site is stable. Otherwise, it is unstable.

(6) Abandoned time. The longer the abandoned time, the smaller the surface residual subsidence is and the more stable the construction site is.

(7) Repeated mining. Under repeated mining, the damage range and failure degree of overburden are larger. Then the construction site is unstable with the stress concentration occurring in surrounding rocks.

(8) Mining degree. The mining degree coefficient $n$ is often used to measure the mining degree of the working face along the strike and the inclination, as expressed in formula 1. There are huge differences in stability with different mining degrees. Under full mining of the working face both along the strike and the inclination, the overburden failure is sufficient. The occurred subsidence is relatively large, and the potential residual subsidence in the future is relatively small. At this point, the construction site is stable. Under insufficiency mining, there are a large number of voids and cavities in the abandoned coal mine, and the potential residual subsidence in the future is relatively large. At this point, the stability of the construction site is relatively poor. In the case of utmost non-full mining, the overburden is damaged in a small range or not damaged, so the overburden is basically complete. Under this condition, the safe operation of the planned expressway almost unaffected with the abandoned coal mine. Accordingly, the stability is not linear related to the mining degree, while changing from high-low-high.

$$
n=\frac{D}{H}
$$

where $D$ is the length of the working face advance. $H$ is the average depth. 
(9) Earthquakes and other vibrations. Affected by the earthquake or other vibrations, the mining secondary equilibrium structure loses stability. New structure is formed, causing a residual deformation in the process. Therefore, when the abandoned coal mine is in the earthquake-prone or other vibration-prone areas, the stability is low.

\section{Stability Evaluation Model}

\subsection{Model Establishing}

The stability evaluation model was established using the overlay and index method. Firstly, the scoring criteria for evaluation indices were determined. Secondly, the indices were scored according to the geological and mining conditions. Then the comprehensive score was obtained by weight overlay. Finally, based on the corresponding relation between comprehensive score and stability level, the stability was obtained. Taking the aforementioned nine factors as evaluation indices, this paper divided them into geology and hydrology, mining and vibration. Figure 2 shows the evaluation model.

$$
\mathrm{R}=\sum_{\mathrm{i}=1}^{4} \alpha_{\mathrm{i}} \mathrm{C}_{\mathrm{i}}+\sum_{\mathrm{j}=1}^{4} \beta_{\mathrm{j}} \mathrm{W}_{\mathrm{j}}+\gamma_{\mathrm{z}} \mathrm{Z}_{\mathrm{z}}
$$

where $\alpha_{\mathrm{i}}, \beta_{\mathrm{j}}$ and $\gamma_{\mathrm{z}}$ are the weights of geologic and hydrological evaluation indices, mining evaluation indices and vibration evaluation indices, respectively, and the sum of weights is $1[18,19] ; C_{i}, W_{j}$ and $Z_{z}$ are the scores (ranging from 1 to 10) of geologic and hydrological evaluation indices, mining evaluation indices and vibration evaluation indices, respectively; $R$ is the comprehensive score.

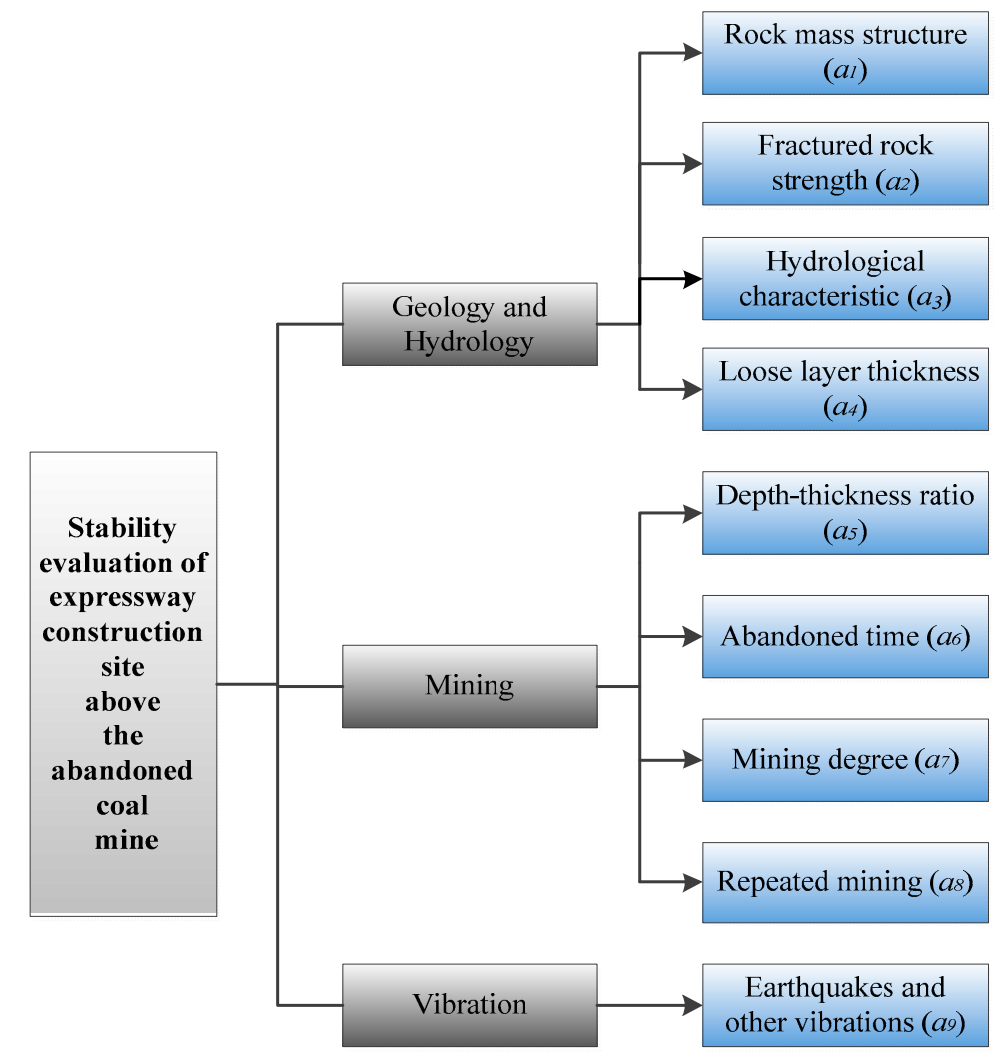

Figure 2. Stability evaluation model.

As can be seen from formula (2), the accuracy degree of the model's evaluation results mainly depended on the scores and weights of the evaluation indices. 


\subsection{Score of the Evaluation Indices}

The lower the score, the higher the construction stability is. The evaluation score can be obtained by referring to their scoring criteria. Therefore, scientific and reasonable scoring criteria were the cornerstone during the whole evaluation process. Considering that there are both quantitative and qualitative indices in the nine evaluation indices mentioned above, the scoring criteria of qualitative indices could be obtained by the equidistant method, while the scoring criteria of quantitative indices could be obtained by establishing scoring functions.

It should be noted that the more stable the construction site is, the smaller the surface residual subsidence is. According to the relationships among the stability of construction site, surface residual subsidence and evaluation score, it can be known that residual subsidence and the evaluation score are positively correlated. It can be concluded that the maximum evaluation score corresponds to the maximum residual subsidence, whereas the minimum evaluation score corresponds to the minimum residual subsidence. Then the equivalent relationship between residual subsidence and the evaluation score is shown in formula (3). In the process of establishing scoring functions, this equivalent relationship may be considered.

$$
\frac{W_{\max }-W}{W_{\max }-W_{\min }}=\frac{V_{\max }-V}{V_{\max }-V_{\min }}
$$

where $W_{\max }$ is the maximum residual subsidence, $W_{\min }$ is the minimum residual subsidence, $V_{\max }$ is the maximum evaluation score and $V_{\min }$ is the minimum evaluation score.

(1) Scoring criterion for the rock mass structure.

The types of rock mass structure in an abandoned coal mine have four situations. (a) The lithology is simply composed of extra-thick sedimentary rocks, metamorphic rocks, volcanic lava and igneous intrusive rocks. There are no more than three groups of structural planes with poor ductility. (b) There are two or three groups of structural planes, which are mainly layer planes. Sometimes, there are soft rock strata or interlayer staggered planes with superior ductility. (c) The rock mass is seriously cut of structural fractures. There are lots of small structural planes with poor ductility. (d) The lithology is complex. Lots of structural planes intersect each other. There are irregular weathering zones and fracture zones. Situation (a) is stable, while situation (d) is unstable. Then the rock mass structure in situations of (a), (b), (c) and (d) are scored using the equidistant method, as shown in Table 2.

Table 2. Relationship between the rock mass structure and evaluation score.

\begin{tabular}{cccccc}
\hline Situations of Abandoned Coal Mine & (a) & (b) & (c) & (d) \\
\hline Evaluation score & 1 & 4 & 7 & 10 \\
\hline
\end{tabular}

(2) Scoring criterion for fractured rock strength.

Through 20 groups of similarity tests of fractured rock, the stress-strain relationship of the fractured rock is expressed in formula (4) $[20,21]$.

$$
\varepsilon=\frac{\varepsilon_{\mathrm{m}}}{10.39 \frac{\sigma_{\mathrm{c}}^{1.042}}{\sigma}\left(1-\varepsilon_{\mathrm{m}}\right)^{7.7} \varepsilon_{\mathrm{m}}+1},
$$

where $\sigma$ is the axial stress; $\varepsilon$ is the axial strain; $\sigma_{\mathrm{c}}$ is the fractured rock strength and $\varepsilon_{\mathrm{m}}$ is the maximum strain of fractured rock, which can be calculated by formula (5).

$$
\varepsilon_{\mathrm{m}}=\frac{\mathrm{M}(1-\mathrm{q} \cdot \cos \alpha)}{\mathrm{h}_{\mathrm{m}}},
$$


where $M$ is the mining height; $h_{m}$ is height of the caving zone; $q$ is the subsidence coefficient ranging from 0.2 to 1.0, and its empirical value can refer to the promulgated regulations (Ministry of Land and Resources of the People's Republic of China 2000) [22] and $\alpha$ is the average angle of the coal seam.

By substituting formula (5) into formula (4), formula (6) is obtained, as follows:

$$
\varepsilon=\frac{\frac{M(1-\mathrm{q} \cdot \cos \alpha)}{\mathrm{h}_{\mathrm{m}}}}{10.39 \frac{\sigma_{\frac{\sigma}{0}}^{1.042}}{\sigma}\left(1-\frac{\mathrm{M}(1-\mathrm{q} \cdot \cos \alpha)}{\mathrm{h}_{\mathrm{m}}}\right)^{7.7} \frac{\mathrm{M}(1-\mathrm{q} \cdot \cos \alpha)}{\mathrm{h}_{\mathrm{m}}}+1} .
$$

Assuming the surface residual subsidence is only caused by the compaction of voids inside the fractured rock, then the residual subsidence $W r$ can be calculated by formula (7).

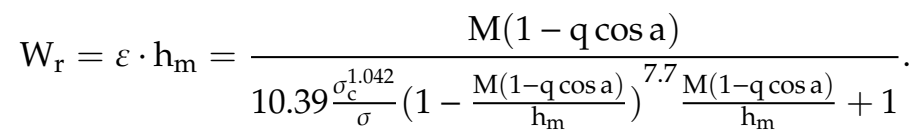

Based on formula (7), four different working conditions were designed. The relationship between residual subsidence and fractured rock strength was obtained, as shown in Figure 3. In all the four working conditions, the residual subsidence reduced to $1 / 2$ when the strength was about $40 \mathrm{MPa}$. It reduced to $1 / 3$ when the strength was about $70 \mathrm{MPa}$. It reduced to $1 / 4$ when the strength was about $100 \mathrm{MPa}$. It reduced to $1 / 5$ when the strength was about $130 \mathrm{MPa}$. It indicates that the residual subsidence decreasing rate was consistent with the fractured rock strength increasing rate. Considering the equivalent relationship of formula (3), the relationship between fractured rock strength and the evaluation score was obtained based on the experimental results, as shown in Figure 4.

As illustrated in Figure 4, a rational function was used to fit the relationship between the fractured rock strength and evaluation score, and the determination coefficient $R^{2}$ was 0.9998 . The fitting formula is expressed in formula (8), which can be adopted as the scoring function for fractured rock strength.

$$
\mathrm{V}=\frac{15.1045}{1+0.0509 \sigma_{\mathrm{c}}} \quad \sigma_{\mathrm{c}} \geq 10 \mathrm{MPa},
$$

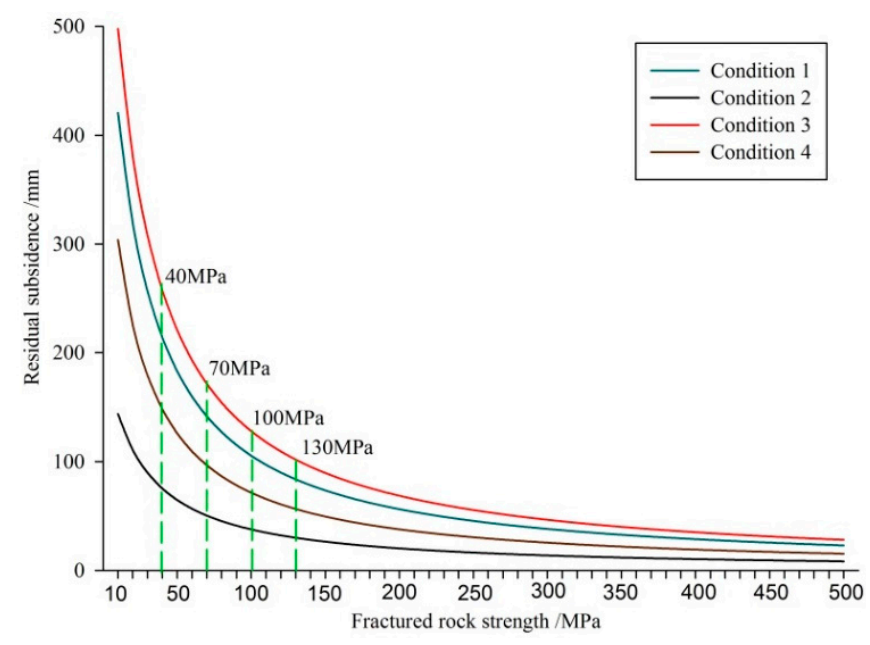

Figure 3. The relationship between residual subsidence and fractured rock strength. 


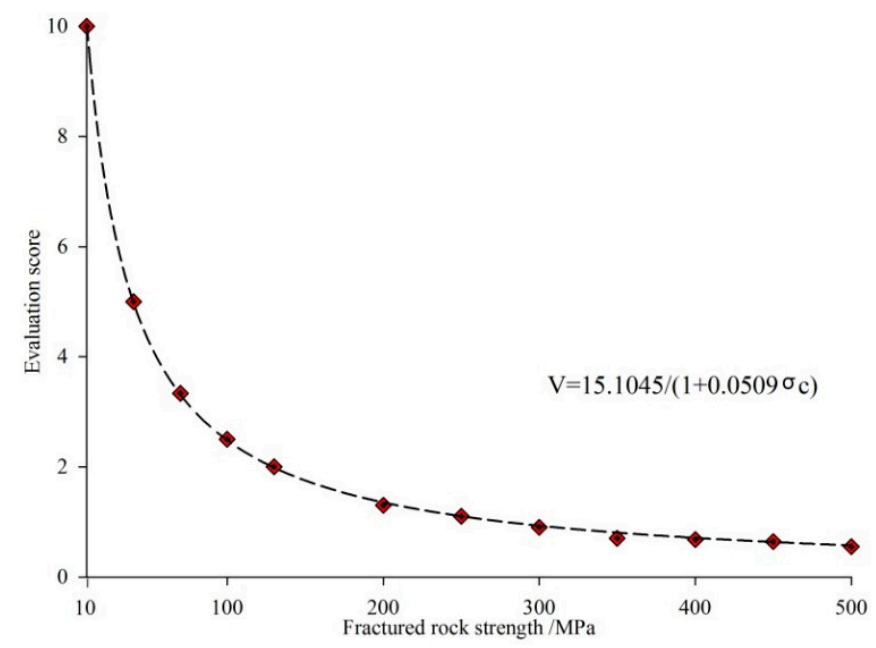

Figure 4. The relationship between the evaluation score and fractured rock strength.

(3) Scoring criterion for the hydrological characteristic.

The types of hydrological characteristics in an abandoned coal mine have four situations. (a) No mine water in the abandoned coal mine. (b) There is a small amount of mine water in the abandoned mine. (c) There is a large amount of mine water in the abandoned mine. (d) The abandoned mine is full of mine water. Situation (a) is stable, while situation (d) is unstable. Then the hydrological characteristics in situations of (a), (b), (c) and (d) are scored using the equidistant method, as shown in Table 3.

Table 3. Relationship between the hydrological characteristic and evaluation score.

\begin{tabular}{cccccc}
\hline Situations of Abandoned Coal Mine & (a) & (b) & (c) & (d) \\
\hline Evaluation score & 1 & 4 & 7 & 10 \\
\hline
\end{tabular}

(4) Scoring criterion for loose layer thickness.

Generally, the soil-rock ratio $s$ is used to reflect the loose layer thickness, which is calculated by formula (9). By establishing four numerical models, the maximum surface residual subsidence was analyzed under different soil-rock ratios using the UDEC (Universal Distinct Element Code). The Mohr-Coulomb failure criterion was selected to describe the failure process of the rock mass. The mechanical parameters are shown in Table 4. It should be noted that the mechanical parameters of fractured rock mass are usually $1 / 5-1 / 3$ of the initial parameters [23].

Table 4. Mechanical parameters of coal and rock mass.

\begin{tabular}{cccccccc}
\hline No. & Name & $\gamma\left(\mathbf{k g} / \mathbf{m}^{\mathbf{3}}\right)$ & $\mathbf{K}(\mathbf{G P a})$ & $\mathbf{G}(\mathbf{G P a})$ & $\mathbf{R m}(\mathbf{M P a})$ & $\mathbf{c}(\mathbf{M P a})$ & $\boldsymbol{\varphi}\left(\left(^{\circ}\right)\right.$ \\
\hline 1 & Topsoil & 1800 & 0.012 & 0.008 & 0.01 & 0.02 & 20 \\
2 & Mudstone & 2200 & 3.960 & 1.810 & 1.21 & 1.56 & 27 \\
3 & Coarse sandstone & 2680 & 16.06 & 13.84 & 1.71 & 3.27 & 32 \\
4 & Fine sandstone & 2630 & 7.000 & 4.500 & 1.80 & 3.47 & 32 \\
5 & Sandy mudstone & 2400 & 2.960 & 2.310 & 1.78 & 2.45 & 31 \\
6 & Coal & 1700 & 2.000 & 1.200 & 0.90 & 0.80 & 25 \\
7 & Siltstone & 2670 & 8.000 & 5.600 & 2.01 & 3.56 & 35 \\
8 & Fractured rock & 2000 & 0.350 & 0.210 & 0.30 & 0.15 & 12 \\
\hline
\end{tabular}

By analyzing the numerical simulation results, the maximum residual subsidence values with different soil-rock ratios were obtained in Figure 5. Considering the equivalent relationship of formula (3), the relationship between the soil-rock ratio and evaluation score was obtained based on the experimental results, as shown in Figure 5. As illustrated in Figure 5, the maximum residual subsidence 
gradually decreased with the soil-rock ratio increasing. An exponential decay function was used to fit the relationship between soil-rock ratio and evaluation score, and the determination coefficient $R^{2}$ was 0.9932. The fitting formula is expressed in formula (10), which can be adopted as the scoring function for the soil-rock ratio (loose layer thickness).

$$
s=\frac{h_{s}}{h_{j}}
$$

where $\mathrm{s}$ is the soil-rock ratio, $h_{s}$ is the loose layer thickness and $h_{j}$ is the bed rock thickness.

$$
V=10 \times e^{-0.528 s} .
$$

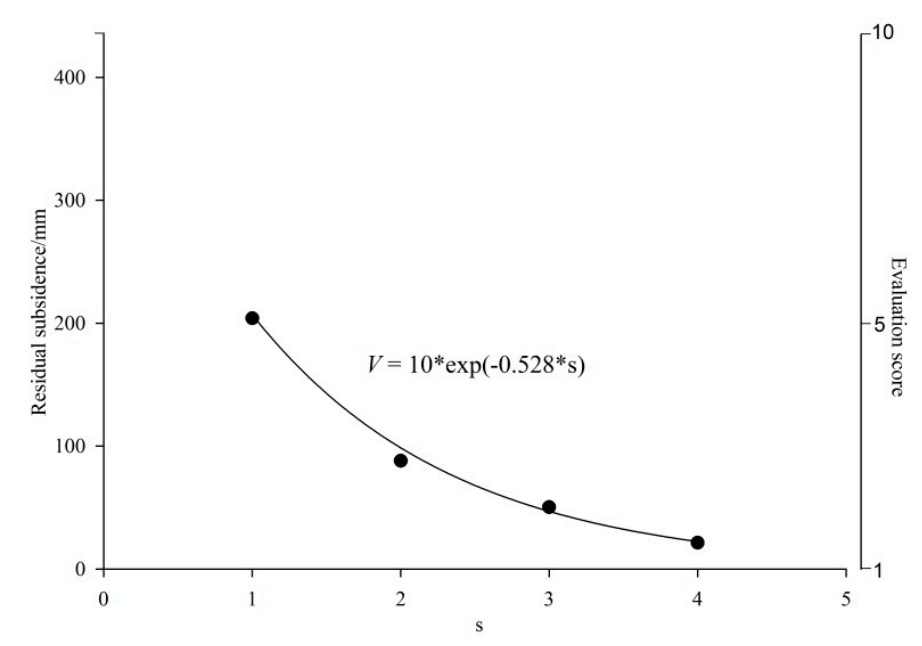

Figure 5. The relationship between the evaluation score and soil-rock ratio.

(5) Scoring criterion for the depth-thickness ratio.

By establishing four numerical models, the residual subsidence was analyzed under different depth-thickness ratios. The mechanical parameters of rock mass are shown in Table 4. By analyzing the numerical simulation results, the maximum residual subsidence of four different depth-thickness ratios was obtained in Figure 6. As illustrated in Figure 6, the maximum residual subsidence gradually decreased with the depth-thickness ratio increasing. When the depth-thickness ratio reached 70, the maximum residual subsidence was less than $10 \mathrm{~mm}$, and the construction site was very stable at this time. Therefore, the evaluation score was set to 1 with the depth-thickness ratio of 70 . When the depth-thickness ratio was 0 , the maximum residual subsidence was extremely large, and the evaluation score was set to 10 with the depth-thickness ratio of 0 . Considering the equivalent relationship of formula (3), the relationship between the depth-thickness ratio and evaluation score was obtained based on the experimental results in Figure 6. When the depth-thickness ratio was between 0-70, a linear function was used to fit the relationship between the depth-thickness ratio and evaluation score, and the determination coefficient $R^{2}$ was 0.9979 . The fitting formula is expressed in formula (11), which can be adopted as the scoring function for the depth-thickness ratio.

$$
\begin{array}{ll}
V=10 & H / M=0 \\
V=-0.1286(H / M)+10 & 0<H / M<70 \\
V=1 & H / M \geq 70
\end{array}
$$




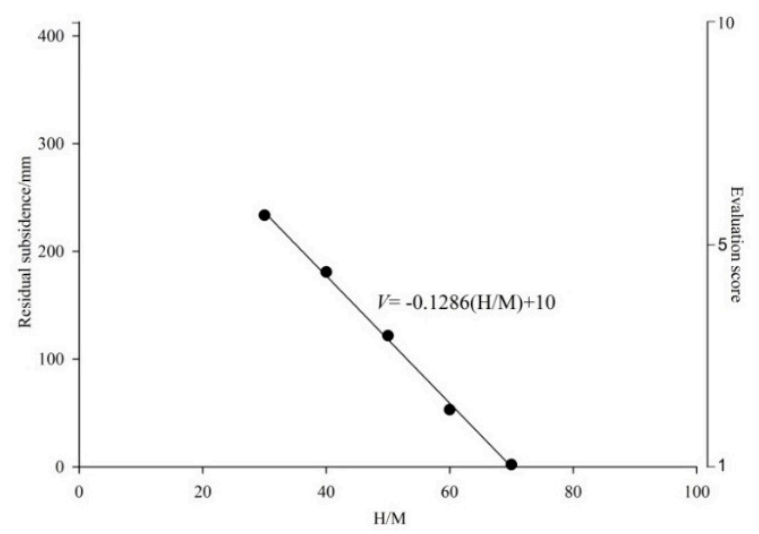

Figure 6. The relationship between the evaluation score and depth-thickness ratio.

(6) Scoring criterion for abandoned time.

According to the measured data in the Xuzhou mining area [8], the relationship between the residual subsidence coefficient $\mathrm{q}^{\prime}$ and abandoned time is shown in Table 5 . The maximum residual subsidence can be calculated using formula (12). When the abandoned time is more than 20 years, the construction site is very stable with no residual subsidence occurring, and the evaluation score can be set to 1 . When the abandoned time is 1 year or less, the residual subsidence is extremely large, and the evaluation score can be set to 10. Considering the equivalent relationship of formula (3), the evaluation scores with different abandoned time are shown in Table 5. An exponential decay function was used to fit the relationship between the abandoned time and evaluation score, as shown in Figure 7 , and the determination coefficient $R^{2}$ was 0.9801 . The fitting formula is expressed in formula (13), which can be adopted as the scoring function for abandoned time.

$$
\begin{array}{rl}
\multicolumn{3}{c}{W_{\max }=M q^{\prime} \cos \alpha,} \\
V=1.3081+10.4886 \times e^{-0.24 a} & 1 \leq a \leq 20 \\
V=1 & a>20
\end{array}
$$

where $a$ is the abandoned time.

Table 5. Relationship between the residual subsidence coefficient $q^{\prime}$ and abandoned time.

\begin{tabular}{ccccccc}
\hline Abandoned Time/a & $\mathbf{1}$ & $\mathbf{2}$ & $\mathbf{5}$ & $\mathbf{1 0}$ & $\mathbf{1 5}$ & More Than 20 \\
\hline Residual subsidence coefficient & 0.25 & 0.175 & 0.1 & 0.062 & 0.025 & 0.01 \\
Evaluation score & 10 & 7.1875 & 4.375 & 2.95 & 1.56 & 1 \\
\hline
\end{tabular}

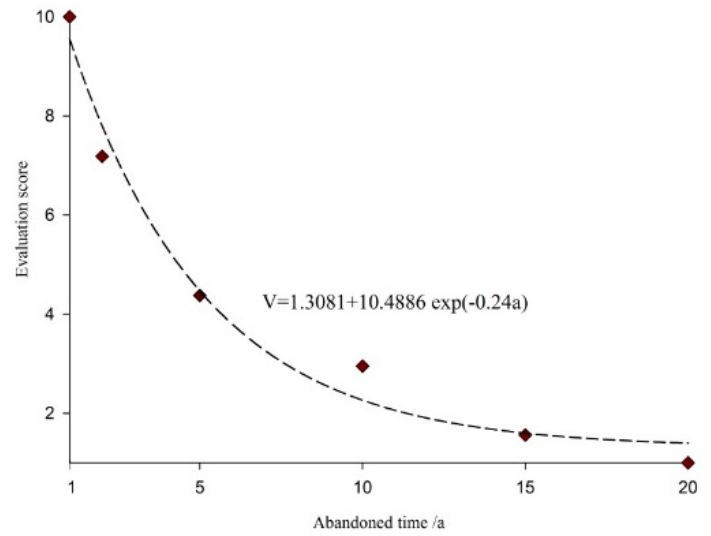

Figure 7. The relationship between the evaluation score and abandoned time.

(7) Scoring criterion for the mining degree. 
By establishing seven numerical models, the surface residual subsidence was analyzed under different mining degrees. The mechanical parameters of rock mass are shown in Table 4 . By analyzing the numerical simulation results, the maximum residual subsidence of seven different mining degrees was obtained in Figure 8. As illustrated in Figure 8, as the mining degree increased, the maximum residual subsidence firstly shows an increasing and then a decreasing trend. Considering the equivalent relationship of formula (3), the relationship between the mining degree and evaluation score was obtained in Figure 8. A modified Gaussian function was used to fit this relationship, and the determination coefficient $R^{2}$ was 0.9639 . The fitting formula is expressed in formula (14), which can be adopted as the scoring function for mining degree.

$$
V=10 \times e^{\left[-0.5\left(\frac{n-0.858}{0.224}\right)^{2}\right]} .
$$

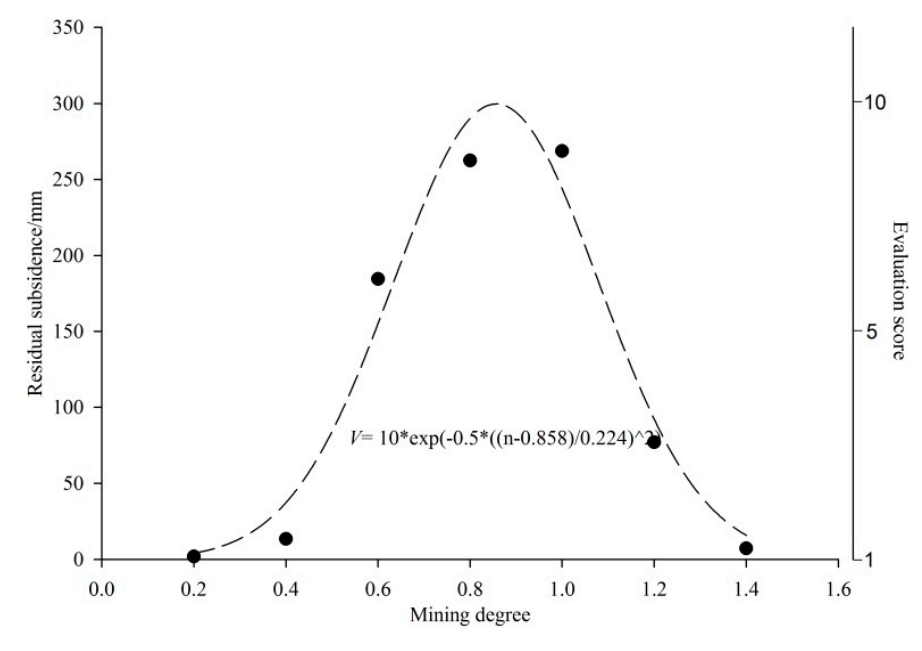

Figure 8. The relationship between the evaluation score and mining degree.

(8) Scoring criterion for repeated mining.

The abandoned coal mine caused by repeated mining can be divided into four situations: (a) Single coal seam mining, (b) the water flowing fractured zone caused by lower coal seam mining does not affect the upper coal seams, (c) the water flowing fractured zone caused by lower coal seam mining is tangent to the upper coal seams and (d) the water flowing fractured zone caused by lower coal seam mining and upper coal seam mining overlaps with each other. Situation (a) is stable, while situation (d) is unstable. Then the repeated mining in situations of (a), (b), (c) and (d) are scored using the equidistant method, as shown in Table 6.

Table 6. Relationship between the repeated mining situations and evaluation score.

\begin{tabular}{ccccc}
\hline Situations of Abandoned Goaf Caused by Repeated Mining & (a) & (b) & (c) & (d) \\
\hline Evaluation score & 1 & 4 & 7 & 10 \\
\hline
\end{tabular}

(9) Scoring criterion for an earthquake and other vibrations.

When the earthquake magnitude is no more than 1, the earthquake almost has no effect on the abandoned coal mine. When the magnitude is more than 4.5 , it is extremely dangerous for the expressway passing through the abandoned coal mine [24]. Thus magnitude 1 and 4.5 of earthquakes are regarded as the threshold values. When the magnitude is less than 1 , the score can be set to 1 . When the magnitude is more than 4.5 , the score can be set to 10 . When the magnitude is more than 1 but less than 4.5 , it is assumed that the evaluation score varies linearly from 1 to 10 . Thus, the relation between 
the earthquake magnitude and the evaluation score was obtained, as expressed in formula (15), which can be adopted as the scoring function for earthquake and other vibrations.

$$
\begin{array}{lc}
V=1 & M_{s} \leq 1 \\
V=-1.5714+2.5714 M_{s} & 1<M_{s}<4.5 \\
V=10 & M_{s} \geq 4.5
\end{array}
$$

where $M_{s}$ is the magnitude.

\subsection{Weight of the Index}

The FAHP (fuzzy analytic hierarchy process) was adopted to determine the weights of the indices, which can solve the difference of consistency between the judgment matrix and expert experience in the AHP (analytic hierarchy process), improving the reliability of weight determination [25]. The fuzzy complementary judgment matrix $A$ is expressed in formula (16).

$$
A=\left(a_{i j}\right)_{n \times n}=\left[\begin{array}{cccc}
a_{11} & a_{12} & \cdots & a_{1 n} \\
a_{21} & a_{22} & \cdots & a_{2 n} \\
\vdots & \vdots & \ddots & \vdots \\
a_{n 1} & a_{n 2} & \cdots & a_{n n}
\end{array}\right],
$$

where the element $a_{i j}$ in this matrix indicates the importance of the index $a_{i}$ relative to the index $a_{j}$. Its value can be referred to Table $7, a_{i i}$ is $0.5, a_{i j}+a_{j i}=1, i, j=1,2, \ldots, n$ and $n=9$.

Table 7. Element value from 0.1-0.9 [25].

\begin{tabular}{cc}
\hline Element Value $\left(a_{i j}\right)$ & Definition \\
\hline 0.5 & Equal importance \\
0.6 & Weak importance \\
0.7 & Essential or strong importance \\
0.8 & Very strong or demonstrated importance \\
0.9 & Absolute importance \\
$0.1,0.2,0.3,0.4$ & Inverse comparison \\
\hline
\end{tabular}

The fuzzy complementary judgment matrix $A$ was constructed by inviting five experts who were familiar with mining subsidence in China. They were from China University of Mining and Technology, China University of Mining and Technology (Beijing), Chang An University, Anhui University and Anhui University of Science and Technology. Integrating the results of these five experts, the final fuzzy complementary judgment matrix $A$ is shown below

$$
A=\left[\begin{array}{lllllllll}
0.500 & 0.400 & 0.700 & 0.300 & 0.200 & 0.100 & 0.400 & 0.300 & 0.700 \\
0.600 & 0.500 & 0.700 & 0.400 & 0.300 & 0.200 & 0.400 & 0.300 & 0.700 \\
0.300 & 0.300 & 0.500 & 0.200 & 0.100 & 0.100 & 0.200 & 0.200 & 0.600 \\
0.700 & 0.600 & 0.800 & 0.500 & 0.300 & 0.200 & 0.600 & 0.400 & 0.800 \\
0.800 & 0.700 & 0.900 & 0.700 & 0.500 & 0.400 & 0.700 & 0.600 & 0.900 \\
0.900 & 0.800 & 0.900 & 0.800 & 0.600 & 0.500 & 0.800 & 0.700 & 0.900 \\
0.600 & 0.600 & 0.800 & 0.400 & 0.300 & 0.200 & 0.500 & 0.400 & 0.800 \\
0.700 & 0.700 & 0.800 & 0.600 & 0.400 & 0.300 & 0.600 & 0.500 & 0.900 \\
0.300 & 0.300 & 0.400 & 0.200 & 0.100 & 0.100 & 0.200 & 0.100 & 0.500
\end{array}\right]
$$


The characteristic matrix $W^{*}$ of fuzzy judgment matrix $A$ can be represented by formula (17).

$$
W^{*}=\left(w_{i j}\right)_{n \times n}=\left[\begin{array}{cccc}
w_{11} & w_{12} & \cdots & w_{1 n} \\
w_{21} & w_{22} & \cdots & w_{2 n} \\
\vdots & \vdots & \ddots & \vdots \\
w_{n 1} & w_{n 2} & \cdots & w_{n n}
\end{array}\right]
$$

where $w_{i j}=\frac{w_{i}}{w_{i}+w_{j}}$ and $w_{i}$ is the weight of index $a_{i}$, which is calculated by formula (18).

$$
w_{i}=\frac{\sum_{j=1}^{n} r_{i j}-1+\frac{n}{2}}{n(n-1)} .
$$

According to formula (17), the characteristic matrix $W^{*}$ of fuzzy judgment matrix $A$ is shown below

$$
W^{*}=\left(w_{i j}\right)_{n \times n}=\left[\begin{array}{ccccccccc}
0.500 & 0.483 & 0.542 & 0.458 & 0.423 & 0.406 & 0.467 & 0.441 & 0.555 \\
0.517 & 0.500 & 0.559 & 0.475 & 0.439 & 0.422 & 0.484 & 0.458 & 0.571 \\
0.458 & 0.441 & 0.500 & 0.417 & 0.382 & 0.366 & 0.426 & 0.400 & 0.513 \\
0.542 & 0.525 & 0.583 & 0.500 & 0.464 & 0.447 & 0.509 & 0.483 & 0.596 \\
0.577 & 0.561 & 0.618 & 0.536 & 0.500 & 0.483 & 0.545 & 0.519 & 0.630 \\
0.594 & 0.578 & 0.634 & 0.553 & 0.517 & 0.500 & 0.562 & 0.536 & 0.646 \\
0.533 & 0.516 & 0.574 & 0.491 & 0.455 & 0.438 & 0.500 & 0.474 & 0.587 \\
0.559 & 0.542 & 0.600 & 0.517 & 0.481 & 0.464 & 0.526 & 0.500 & 0.612 \\
0.445 & 0.429 & 0.487 & 0.404 & 0.370 & 0.354 & 0.413 & 0.388 & 0.500
\end{array}\right]
$$

The compatibility index of $A$ and $W^{*}$ can be determined using formula (19). The calculated result shows that the fuzzy complementary judgment matrix $A$ does not meet the consistency requirement with the obtained compatibility index $I\left(A, W^{*}\right)$ of $0.259>0.200$ (higher-order matrix) [26,27], and the indices weights are not scientific and reasonable.

$$
I\left(A, W^{*}\right)=\frac{1}{n^{2}} \sum_{i=1}^{n} \sum_{j=1}^{n}\left|a_{i j}+w_{i j}-1\right| .
$$

In order to meet the consistency requirement, it is necessary to adjust the fuzzy complementary judgment matrix $A$ to the fuzzy consistent matrix $R$ by formula (20).

$$
R=\left(r_{i j}\right)_{n \times n}=\left[\begin{array}{cccc}
r_{11} & r_{12} & \cdots & r_{1 n} \\
r_{21} & r_{22} & \cdots & r_{2 n} \\
\vdots & \vdots & \ddots & \vdots \\
r_{n 1} & r_{n 2} & \cdots & r_{n n}
\end{array}\right],
$$

where $r_{i j}=\frac{r_{i}-r_{j}}{2(n-1)}+0.5$ and $r_{i}=\sum_{j=1}^{n} a_{i j}$. 
According to formula (20), the fuzzy consistent matrix $R$ is shown below:

$$
R=\left[\begin{array}{lllllllll}
0.500 & 0.469 & 0.569 & 0.419 & 0.344 & 0.300 & 0.444 & 0.388 & 0.588 \\
0.531 & 0.500 & 0.600 & 0.450 & 0.369 & 0.325 & 0.469 & 0.413 & 0.619 \\
0.431 & 0.400 & 0.500 & 0.350 & 0.269 & 0.225 & 0.369 & 0.313 & 0.519 \\
0.581 & 0.550 & 0.650 & 0.500 & 0.419 & 0.375 & 0.519 & 0.463 & 0.669 \\
0.656 & 0.631 & 0.731 & 0.581 & 0.500 & 0.456 & 0.600 & 0.544 & 0.750 \\
0.700 & 0.675 & 0.775 & 0.625 & 0.544 & 0.500 & 0.644 & 0.588 & 0.794 \\
0.556 & 0.531 & 0.631 & 0.481 & 0.400 & 0.356 & 0.500 & 0.444 & 0.650 \\
0.613 & 0.588 & 0.688 & 0.538 & 0.456 & 0.413 & 0.556 & 0.500 & 0.706 \\
0.413 & 0.381 & 0.481 & 0.331 & 0.250 & 0.206 & 0.350 & 0.294 & 0.500
\end{array}\right]
$$

Then the characteristic matrix $W_{R}^{*}$ of fuzzy consistent matrix $R$ is shown below using formula (17).

$$
W_{R}^{*}=\left[\begin{array}{lllllllll}
0.500 & 0.492 & 0.522 & 0.478 & 0.457 & 0.446 & 0.483 & 0.468 & 0.529 \\
0.508 & 0.500 & 0.531 & 0.486 & 0.465 & 0.454 & 0.491 & 0.476 & 0.537 \\
0.478 & 0.469 & 0.500 & 0.455 & 0.434 & 0.424 & 0.461 & 0.446 & 0.506 \\
0.522 & 0.514 & 0.545 & 0.500 & 0.479 & 0.468 & 0.505 & 0.490 & 0.551 \\
0.543 & 0.535 & 0.566 & 0.521 & 0.500 & 0.489 & 0.526 & 0.511 & 0.572 \\
0.554 & 0.546 & 0.576 & 0.532 & 0.511 & 0.500 & 0.537 & 0.522 & 0.582 \\
0.517 & 0.509 & 0.539 & 0.495 & 0.474 & 0.463 & 0.500 & 0.485 & 0.546 \\
0.532 & 0.524 & 0.554 & 0.510 & 0.489 & 0.478 & 0.515 & 0.500 & 0.561 \\
0.471 & 0.463 & 0.494 & 0.449 & 0.428 & 0.418 & 0.454 & 0.439 & 0.500
\end{array}\right]
$$

The compatibility index $I\left(R, W_{R}^{*}\right)$ is $0.136<0.200$. That is, the fuzzy consistent matrix $R$ can meet the consistency requirement, and the indices weights are scientific and reasonable. According to formula (18), the weights of evaluation indices $W_{1}, W_{2}, W_{3}, W_{4}, W_{5}, W_{6}, W_{7}, W_{8}$ and $W_{9}$ are 0.104 , $0.108,0.095,0.114,0.124,0.130,0.112,0.119$ and 0.093 , respectively.

\subsection{Stability Level Classification}

The stability level is divided into stable, basic stable, unstable and instability. According to formula (2), the comprehensive evaluation score $R$ is randomly distributed from 1 to 10 , and the relationship between comprehensive evaluation score $R$ and stability level is obtained using the equidistant method, as shown in Table 8.

Table 8. Stability level of the expressway construction site above an abandoned coal mine.

\begin{tabular}{ccccc}
\hline Stability Level Classification & Stable & Basic Stable & Unstable & Instability \\
\hline Comprehensive score & $1 \leq \mathrm{R}<3.25$ & $3.25 \leq \mathrm{R}<5.50$ & $5.50 \leq \mathrm{R}<7.75$ & $7.75 \leq \mathrm{R} \leq 10$ \\
\hline
\end{tabular}

\section{Results and Discussion}

\subsection{Stability Evaluation of the Wuyun Expressway Construction Site}

On the basis of the previous research results, the scoring criteria and weights of nine evaluation indices were obtained, as shown in Table 9. According to the geological and mining conditions of investigated area, the rock mass under Wuyun expressway was relatively complete. The basic structure was a monoclinal structure striking SE in the zone. There were a small number of faults under $\mathrm{K} 30+520-\mathrm{K} 29+650$ and $\mathrm{K} 29+520-\mathrm{K} 29+650$. The water seepage was small around the abandoned coal mine. The soil-rock ratio $s$ (loose layer thickness) was 2.8. The average depth-thickness ratio was more than 100. The earthquake magnitude was about 5.5. Referring to the indices scoring criteria, the evaluation scores of indices for the Wuyun expressway construction site are shown in Table 9. 
Table 9. Scores of evaluation indices of the Wuyun expressway.

\begin{tabular}{|c|c|c|c|c|}
\hline Index & Weight & Scoring Criterion & Wuyun Expressway & Evaluation Score \\
\hline Rock mass structure $\left(a_{1}\right)$ & 0.104 & $\begin{array}{l}\text { Equidistant method } \\
\text { (Table 2) }\end{array}$ & Situation $(b)$ & 4.0 \\
\hline Fractured rock strength $\left(a_{2}\right)$ & 0.108 & $\begin{array}{c}\mathrm{V}=15.1045 /\left(1+0.0509 \sigma_{\mathrm{c}}\right), \sigma_{\mathrm{c}} \geq 10 \\
\mathrm{MPa}\end{array}$ & $28 \mathrm{MPa}$ & 6.2 \\
\hline $\begin{array}{c}\text { Hydrological characteristic } \\
\left(a_{3}\right)\end{array}$ & 0.095 & $\begin{array}{l}\text { Equidistant method } \\
\text { (Table 3) }\end{array}$ & Situation $(b)$ & 4.0 \\
\hline Loose layer thickness $\left(a_{4}\right)$ & 0.114 & $\mathrm{~V}=10 \times \mathrm{e}^{-0.528 \mathrm{~s}}$ & 2.8 & 2.3 \\
\hline Depth-thickness ratio $\left(a_{5}\right)$ & 0.124 & $\begin{array}{c}\mathrm{V}=-0.1286(\mathrm{H} / \mathrm{M})+10 \\
0 \leq \mathrm{H} / \mathrm{M}<70 \\
\mathrm{~V}=1 \\
\mathrm{H} / \mathrm{M} \geq 70\end{array}$ & 100 & 1 \\
\hline Abandoned time $\left(a_{6}\right)$ & 0.130 & $\begin{array}{c}\mathrm{V}=1.3081+10.4886 \times \mathrm{e}^{-0.24 a} \\
1 \leq a \leq 20 \\
\mathrm{~V}=1 \\
a>20\end{array}$ & 6 & 3.8 \\
\hline Mining degree $\left(a_{7}\right)$ & 0.112 & $\mathrm{~V}=10 \times \mathrm{e}^{\left(-0.5((\mathrm{n}-0.858) / 0.224)^{\wedge} 2\right)}$ & 1.3 & 1.4 \\
\hline Repeated mining $\left(a_{8}\right)$ & 0.119 & $\begin{array}{l}\text { Equidistant method } \\
\text { (Table 6) }\end{array}$ & Situation $(a)$ & 1 \\
\hline $\begin{array}{c}\text { Earthquakes and other } \\
\text { vibrations }\left(a_{9}\right)\end{array}$ & 0.093 & $\begin{array}{c}\mathrm{V}=1 \\
M_{S} \leq 1 \\
\mathrm{~V}=-1.5714+2.5714 M_{S} \\
1<M_{S}<4.5 \\
\mathrm{~V}=10 \\
M s \geq 4.5\end{array}$ & 5.5 & 10 \\
\hline
\end{tabular}

The comprehensive assessment score $\mathrm{R}$ of the Wuyun expressway was 3.5516 by substituting scores and weights into formula (2). According to Table 8, the stability level of the Wuyun expressway is basic stable. This evaluation result is consistent with the earlier result, which it got using the fuzzy theory [28]. A simple anti-deformation design can ensure safe operation. Therefore, it is proposed to apply geogrids in subgrade to improve its anti-deformation ability and avoid potential threats.

\subsection{Sensitivity Analysis of Indices Weights}

It should be pointed out the fuzzy complementary judgment matrix $A$ mainly relies on expert experience. The weight determination process does not completely exclude the subjective influence, and the evaluation result cannot be considered as the unique value. In order to prove the evaluation result, the OAT (one at a time) is adopted to analyze the influence of weight uncertainty on the result $[29,30]$. The process of OAT is as follows:

(1) Defining the RPC (range of percent change). RPC is a finite set of discrete percentage changes with original basic data. The RPC was set to $\pm 30 \%$ in this work.

(2) Defining the IPC (increment of percent change). IPC is the percentage of weight change in the range of RPC. The IPC was set to $\pm 4 \%$ in this work.

(3) Changing evaluation indices weights using formula (21) and (22).

$$
\begin{gathered}
W\left(C_{m}, p c\right)=W\left(C_{m}, 0\right)+W\left(C_{m}, 0\right) \cdot p c, \\
W\left(C_{i}, p c\right)=\left(1-W\left(C_{m}, p c\right)\right) \cdot \frac{W\left(C_{i}, 0\right)}{\left(1-W\left(C_{m}, 0\right)\right)},
\end{gathered}
$$

where pc is weight changing percentage of the weight change, which is an integer multiple of IPC; $W\left(C_{m}, p c\right)$ is the weight of primary index after change; $W\left(C_{m}, 0\right)$ is the initial weight of primary index; $W\left(C_{i}, p c\right)$ is the weight of some other index after change and $W\left(C_{i}, 0\right)$ is the initial weight of some other index.

(4) Calculating the comprehensive score $R\left(C_{m}, p c\right)$ after weights change. 
(5) Calculating the comprehensive score change rate using formula (23).

$$
C_{k}\left(C_{m}, p c\right)=\frac{R\left(C_{m}, p c\right)-R_{0}}{R_{0}} \times 100 \%,
$$

where $C_{k}\left(C_{m}, p c\right)$ is the comprehensive score change rate.

(6) Repeating steps (3)-(5) until each evaluation index is rotating as the primary factor.

According to the above steps, a total of 135 groups of weights are generated, and the comprehensive scores calculated by 135 groups of weights are shown in Figure 9.

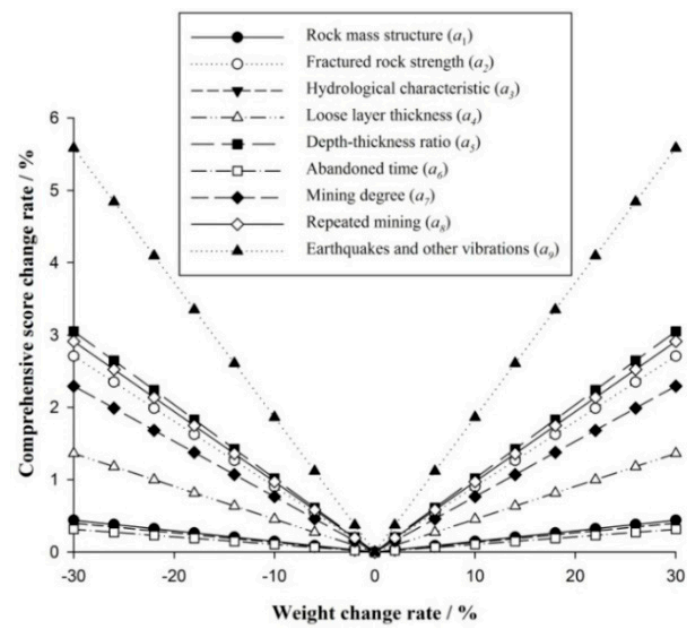

Figure 9. Comprehensive score change rate.

As illustrated in Figure 9, the comprehensive score change rate was a centrosymmetric distribution with the weight change rate of $0 \%$, and increased with weight change rate increasing. The sensitivity of the evaluation index weight to the result was positively correlated with the slope. The greater the slope, the higher sensitivity was. Therefore, the sensitivity of evaluation index $\left(a_{8}\right)$ to weight change was the highest in all nine evaluation indices, while the sensitivity of the evaluation index $\left(a_{5}\right)$ to weight change was the lowest. Taking the evaluation index $\left(a_{8}\right)$ as an example, the $C_{k}\left(C_{m}, p c\right)$ was $5.9 \%$, which was far lower than the weight change of $\pm 30 \%$, indicating that the evaluation result in this paper was stable and reliable. In conclusion, the determined weights were reliable and effective, which could be used to evaluate the stability of the construction site correctly and objectively.

\subsection{Subsidence Monitoring of the Construction Site}

To analyze the reliability of the proposed evaluation model, a high-resolution leveling was carried out in the field measurement from 20 September 2016 to 10 December 2018 to obtain the subgrade subsidence. The measurement result is shown in Figure 10. As illustrated in Figure 10, the subsidence increased firstly, and then tended to be stable. After 14 October 2017, the subsidence reached its maximum value basically, and the maximum subsidence was about $37 \mathrm{~mm}$. The average residual subsidence velocity of the maximum subsidence point was about $0.0456 \mathrm{~mm} /$ day. Therefore, it could be concluded that the construction site was basically stable, proving the credibility of evaluation result indirectly. 


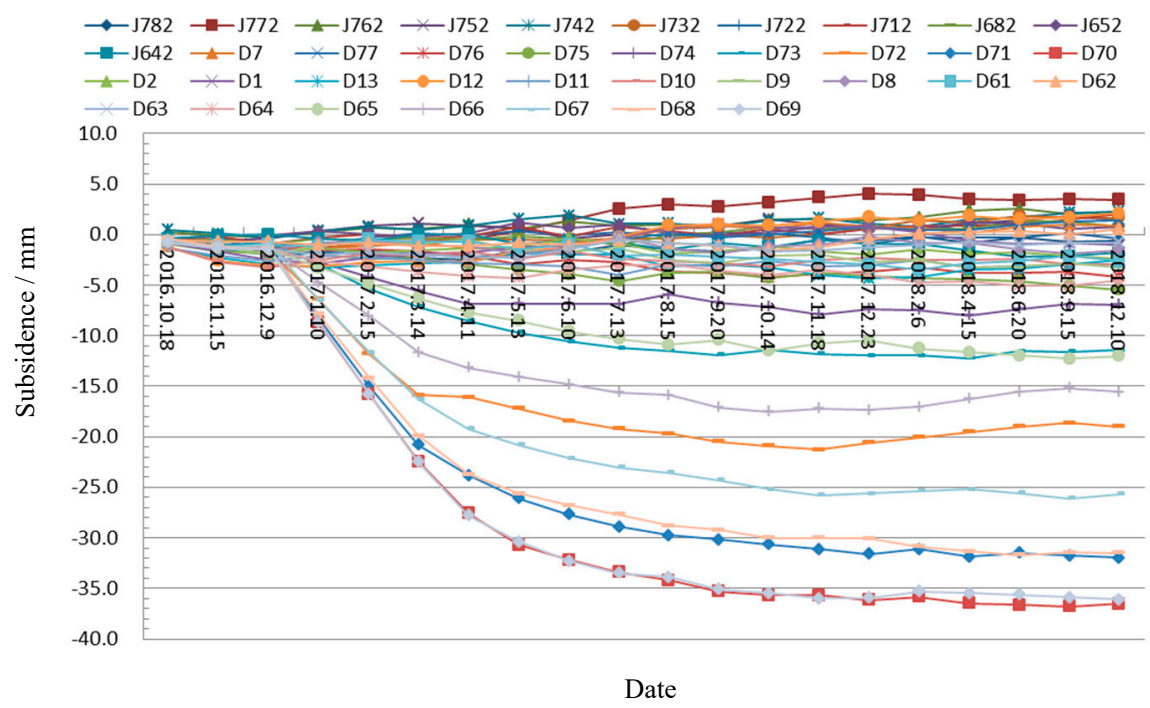

Figure 10. The subsidence monitoring result.

\section{Conclusions}

The stability evaluation model for the expressway construction site above an abandoned coal mine was established based on the overlay and index method. This proposed model was efficient and practical, which could obtain the evaluation result by simple linear superposition, but the reliability of the evaluation result mainly depends on the weights and scores of indices. In this paper, the weights of all indices were obtained using FAHP, and the sensitivity of indices weights on the evaluation result was analyzed, indicating the determined weights were reliable and effective. The scoring criteria of qualitative indices were obtained by the equidistant method such as the rock mass structure $\left(a_{1}\right)$, hydrological characteristic $\left(a_{3}\right)$ and repeated mining $\left(a_{8}\right)$. The scoring criteria of quantitative indices were obtained by scoring functions considering the equivalent relationship between residual subsidence and evaluation score, such as fractured rock strength $\left(a_{2}\right)$, loose layer thickness $\left(a_{4}\right)$, the depth-thickness ratio $\left(a_{5}\right)$, abandoned time $\left(a_{6}\right)$, mining degree $\left(a_{7}\right)$ and earthquake and other vibrations $\left(a_{9}\right)$. The weights and scoring criteria obtained in this paper would provide a reference for the future research of similar projects.

Applying the proposed model to the Wuyun expressway construction site, the evaluation result shows that the investigated area was basic stable. Field measurement shows that the maximum subsidence was $37 \mathrm{~mm}$ in more than 2 years, and the average residual subsidence velocity was about $0.0456 \mathrm{~mm} / \mathrm{d}$, proving the credibility of the evaluation result indirectly.

It should be noted that the proposed evaluation model was only suitable for the abandoned coal mine caused by longwall mining, and the selected indices and their weights and scoring criteria were not suitable for strip mining and filling mining. In a future study, the proposed evaluation model should be established by analyzing the characteristics of overburden failure and the residual deformation mechanism in strip mining and filling mining to make up the research results in this paper.

Author Contributions: Conceptualization, Q.G.; Data curation, X.Z.; Formal analysis, G.G.; Funding acquisition, Q.G., Y.L., L.W. and X.Z.; Investigation, L.W.; Methodology, Q.G.; Resources, G.G.; Supervision, X.Z.

Funding: This research was funded by the Natural Science Foundation of China $(51904008,51574006,41602357$, 41704008), the Research Fund of The State Key Laboratory of Coal Resources and safe Mining, CUMT (SKLCRSM19KF005), the Natural Science Foundation of Anhui Colleges (KJ2019A0135), the Pre-research project of the Natural Science Foundation of Anhui University of Science \& Technology (YY201802), and the Start-up Foundation of Anhui University of Science \& Technology (11953).

Acknowledgments: We would like to thank the five anonymous reviewers for their constructive suggestions.

Conflicts of Interest: The authors declare that they have no conflicts of interest. 


\section{References}

1. Qian, M.G.; Xu, J.L.; Wang, J. Further on the sustainable mining of coal. J. China Coal Soc. 2018, 1, 1-13. [CrossRef]

2. Yuan, L. Strategies of high efficiency recovery and energy saving for coal resources in China. J. China Univ. Min. Technol. (Soc. Sci.) 2018, 1, 3-12.

3. Xie, H.P.; Wang, J.H.; Shen, B.H.; Liu, J.Z.H.; Jiang, P.F.; Zhou, H.W.; Liu, H.; Wu, G. New idea of coal mining: Scientific mining and sustainable mining capacity. J. China Coal Soc. 2012, 7, 1069-1079. [CrossRef]

4. Guo, Q.B. Research on the Safety Evaluation and Key Technologies for the Expressway Construction on Old Goaf of Coal Mine. Ph.D. Thesis, China University of Mining and Technology, Xuzhou, China, 2017.

5. Guéguen, Y.; Deffontaines, B.; Fruneau, B.; de Michelec, M.; Raucoulesc, D.; Guisec, Y.; Planchenaultc, J. Monitoring residual mining subsidence of Nord/Pas-de-Calais coal basin from differential and Persistent Scatterer Interferometry (Northern France). J. Appl. Geophys. 2009, 4, 24-34. [CrossRef]

6. Grgic, D.; Giraud, A.; Auvray, C. Impact of chemical weathering on micro/macro-mechanical properties of oolithic iron ore. Int. J. Rock Mech. Min. Sci. 2013, 64, 236-245. [CrossRef]

7. Salmi, E.F.; Nazem, M.; Karakus, M. The effect of rock mass gradual deterioration on the mechanism of post-mining subsidence over shallow abandoned coal mines. Int. J. Rock Mech. Min. Sci. 2017, 91, 59-71. [CrossRef]

8. Guo, G.L. Foundation Deformation Mechanism and Its Control over Old Goaf; China University of Mining and Technology Press: Xuzhou, China, 2001.

9. Che, A.G.; Guo, Q.B.; Guo, G.L.; Yang, F. Stability evaluation of construction site for goaf section of Wuzhi-Yuntaishan expressway based on stochastic medium theory. Highway 2016, 12, 53-57.

10. Gajović, V.; Kerkez, M.; Kočović, J. Modeling and simulation of logistic processes: Risk assessment with a fuzzy logic technique. Simul. Trans. Soc. Model. Simul. Int. 2017, 1-12. [CrossRef]

11. Yu, J.; Guo, L.; Ma, M.; Kamel, S.; Li, W.; Song, X. Risk assessment of integrated electrical, natural gas and district heating systems considering solar thermal CHP plants and electric boilers. Electr. Power Energy Syst. 2018, 103, 277-287. [CrossRef]

12. Jin, L.X.; Feng, Q.X. Improved radial movement optimization to determine the critical failure surface for slope stability analysis. Environ. Earth Sci. 2018, 77, 564. [CrossRef]

13. Saffari, A.; Ataei, M.; Sereshki, F.; Naderi, M. Environmental impact assessment (EIA) by using the Fuzzy Delphi Folchi (FDF) method (case study: Shahrood cement plant, Iran). Environ. Dev. Sustain. 2019, 21, 817-860. [CrossRef]

14. Xue, Y.G.; Li, Z.H.Q.; Li, S.H.; Qiu, D.H.; Su, M.X.; Xu, Z.H.; Zhou, B.H.; Tao, Y.F. Water inrush risk assessment for an undersea tunnel crossing a fault: An analytical model. Mar. Georesour. Geotechnol. 2019, 37, 816-827. [CrossRef]

15. Hu, O.Y. Study on Comprehensive Evaluation of Transmission Grid Planning Based on Improved Fuzzy-AHP. Master's Thesis, North China Electric Power University, Beijing, China, 2016.

16. Lee, D.K.; Mojtabai, N.; Lee, H.B.; Song, W.K. Assessment of the influencing factors on subsidence at abandoned coal mines in South Korea. Environ. Earth Sci. 2014, 68, 647-654. [CrossRef]

17. Cui, X.; Gao, Y.; Yuan, D. Sudden surface collapse disasters caused by shallow partial mining in Datong coalfield, China. Nat. Hazards 2014, 74, 911-929. [CrossRef]

18. Boufekane, A.; Saighi, O. Application of Groundwater Vulnerability Overlay and Index Methods to the Jijel Plain Area (Algeria). Grounwater 2018, 56, 143-156. [CrossRef] [PubMed]

19. Shrestha, S.; Kafle, R.; Pandey, V.P. Evaluation of index-overlay methods for groundwater vulnerability and risk assessment in Kathmandu Valley, Nepal. Sci. Total Environ. 2017, 575, 779-790. [CrossRef] [PubMed]

20. Salamon, M.D.G. Mechanism of caving in longwall mining. Rock Mechanics Contributions and Challenges. In Proceedings of the 31st US Symposium, Golden, Colorado, 18-20 June 1990; pp. 161-168.

21. Deng, K.Z.; Tan, Z.X.; Zhang, H.Z.; Fan, H.D.; Zhang, L.Y. Research on calculating method of residual subsidence of longwall goaf. J. China Coal Soc. 2012, 37, 1601-1605.

22. Ministry of Land and Resources of the People's Republic of China. Coal Mining under the Buildings, Water Bodies and Railways; China Coal Industry Publishing Home: Beijing, China, 2000.

23. Tong, L.Y.; Qiu, Y.; Liu, S.Y.; Fang, L. Discussion of interaction law of expressway and underlying mine goafs. Chin. J. Rock Mech. Eng. 2010, 29, 2271-2276. 
24. Wang, Z.S. Study on the Non-linear Prediction Theory of Old Goaf Residual Subsidence and Its Application. Ph.D. Thesis, China University of Mining and Technology, Xuzhou, China, 2011.

25. Lu, Q.Y.; Li, X.Q.; Li, W.P.; Chen, W.; Li, L.F.; Liu, S.L. Risk evaluation of bed-separation water inrush: A case study in the Yangliu coal mine, China. Mine Water Environ. 2018, 33, 288-299. [CrossRef]

26. Song, G.X.; Yang, D.L. Methods for identifying and improving the consistency of fuzzy judgment matrix. Syst. Eng. 2003, 21, 110-116.

27. Wang, M.W.; Wu, D.G.; Zhang, W.W. Application of RAGA-based fuzzy analytic hierarchy process to optimization of blasting plans. Explos. Shock Waves 2008, 28, 225-228.

28. Yang, F.; Guo, G.L.; Wan, Z.H.S.H.; Guo, Q.B. Stability evaluation of the expressway construction site on the old goaf of coal mine. Metal Mine 2017, 11, 137-144.

29. Zhao, X.J.; Ye, Y.; Zhou, J.H.; Liu, L.; Dai, W.J.; Wang, Q.X.; Hu, Y.M. Comprehensive evaluation of cultivated land quality and sensitivity analysis of index weight in hilly region of Pearl River Delta. Trans. Chin. Soc. Agric. Eng. (Trans. CSAE) 2017, 33, 226-235.

30. Chen, Y.; Yu, J.; Khan, S. Spatial sensitivity analysis of multi-criteria weights in GIS-based land suitability evaluation. Environ. Model. Softw. 2010, 25, 1582-1591. [CrossRef]

(C) 2019 by the authors. Licensee MDPI, Basel, Switzerland. This article is an open access article distributed under the terms and conditions of the Creative Commons Attribution (CC BY) license (http://creativecommons.org/licenses/by/4.0/). 